\title{
Actuaciones de reconocimiento y valoración del patrimonio arqueológico subacuático del litoral andaluz
}

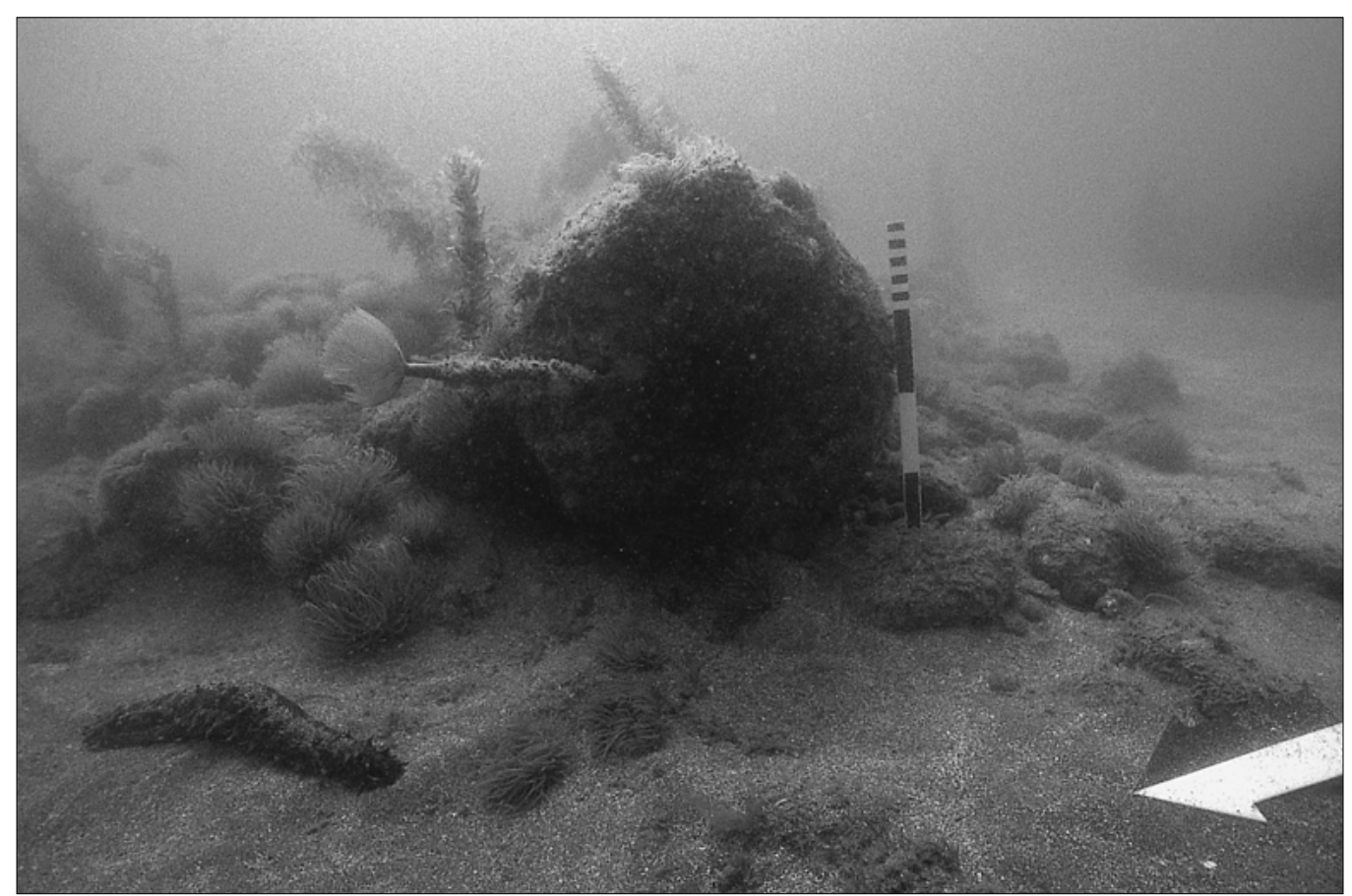

\section{Nuria Rodríguez Mariscal} Milagros Alzaga García

Centro de Arqueología Subacuática del IAPH

\section{Resumen}

Ante la necesidad de conocer y valorar el Patrimonio Arqueológico Subacuático de Andalucía, y tomando como base los datos obtenidos en trabajos anteriores, se seleccionaron una serie de yacimientos de cada una de las provincias con el objeto de determinar su existencia y evaluar el grado de deterioro de cada uno de ellos.

\section{Palabras Clave}

Patrimonio Arqueológico Subacuático / Litoral andaluz / Yacimientos / Bases de Datos / Localización / Conservación

\section{INTRODUCCIÓN}

A lo largo de 1997 el Centro de Arqueología Subacuática (CAS) puso en marcha el proyecto "Documentación y análisis del riesgo antrópico del patrimonio arqueológico subacuático de Andalucía", tras un año de trabajos llevados a cabo en las cinco provincias marítimas se pudieron establecer las siguientes conclusiones:

- se han creado las bases para la recopilación de información documental y material, relativa tanto a los 


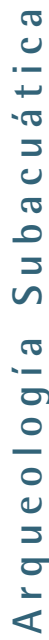

principales agentes de riesgo, con el fin de llegar a conocer la existencia de yacimientos sumergidos, así como su posible localización.

- necesidad de realizar prospecciones en las distintas áreas estudiadas para poder situar aquellos yacimientos de los cuales se posee una información archivística u oral. Sólo conociendo su ubicación exacta podrán ser objeto de unas medidas de protección adecuadas, sobre todo si se tiene presente el importante incremento que la presión antrópica está ejerciendo sobre las costas y fondos marinos, provocando un grave deterioro o destrucción.

- la documentación arqueológica que se posee sobre los yacimientos y zonas ya trabajadas es insuficiente, dado que la Administración autonómica carece de los informes de las intervenciones que se llevaron a cabo con anterioridad al traspaso de competencias (1985), desde el Gobierno Central.

- este trabajo ha sentado las bases sobre las que continuar la labor documental y de constatación real del estado del patrimonio arqueológico subacuático (PAS), a pesar del retraso con respecto a la arqueología terrestre y a la escasez de documentación elaborada de la que se dispone. No se debe olvidar que sólo la labor preventiva puede ofrecer resultados positivos a la hora de salvaguardar nuestro patrimonio.

A estas conclusiones habría que añadir que el II Plan General de Bienes Culturales tiene entre sus fines:

- asegurar la preservación de los bienes culturales para el futuro.

- identificar el patrimonio histórico andaluz y sistematizar su información, reconociendo su diversidad y distribución territorial, determinando el grado de riesgo a que está sometido y transmitiendo su valor y vulnerabilidad a la sociedad.
- adoptar medidas para evitar o minimizar los problemas de conservación del patrimonio histórico andaluz, actuando sobre las causas que provocan su degradación.

En este sentido, y teniendo presente la obligación que la Administración tiene de tutelar el patrimonio, el CAS se planteó la necesidad de programar periódicamente unas actuaciones encaminadas a localizar y valorar yacimientos a lo largo de todo el litoral andaluz. El hecho de que actualmente exista un enorme desfase entre los yacimientos terrestres y subacuáticos recogidos en el Inventario de Yacimientos Arqueológicos de Andalucía (IYAA) se traduce en una deficiente labor de protección como consecuencia del escaso conocimiento que se posee sobre el PAS.

Con estos antecedentes se definieron los siguientes objetivos:

- actualizar la información sobre el estado de los yacimientos incluídos en la base de datos ARQUEOS.

- localizar y valorar los yacimientos recogidos en la base de datos YACSUB, compuesta principalmente por noticias orales de buceadores, pescadores y gentes del mar, donde se hace referencia a la existencia de restos arqueológicos. Se trataría de puntos concretos a inspeccionar.

- trasladar a las Delegaciones Provinciales de Cultura toda información obtenida de cada uno de los yacimientos o zonas, con el fin de mejorar el conocimiento que se tiene sobre los mismos.

Dada la gran extensión del litoral andaluz -750 Km- se optó por hacer una selección de los yacimientos a visitar dentro de cada provincia, teniendo en cuenta la concentración de los mismos, el riesgo de expolio y el peligro de destrucción o alteración por obras de infraestructura. Así, se estableció la siguiente relación: (Fig. I)

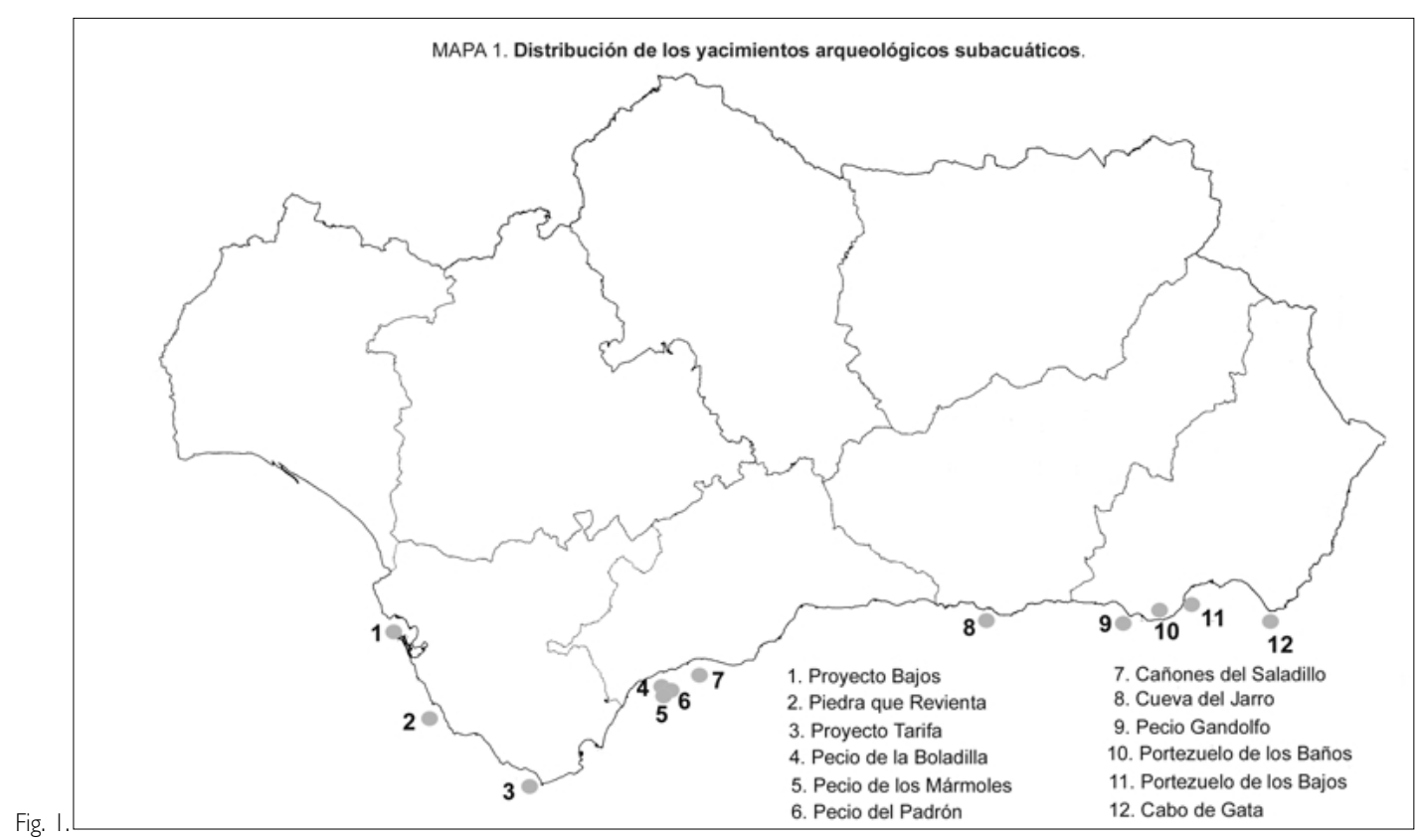




\begin{tabular}{|l|l|l|}
\hline \multicolumn{1}{|c|}{ PROVINCIA } & \multicolumn{1}{|c|}{ ARQUEOS } & \multicolumn{1}{c|}{ YACSUB } \\
\hline \multirow{4}{*}{ HUELVA } & Bajo del Picacho & \\
\cline { 2 - 3 } & Pecio Moderno & \\
\hline & Puente Carranza & \\
\hline & Caño Sancti-Petri & Proyecto Bajos al NW de Cádiz \\
\hline & Proyecto Bajos al NW de Cádiz & Proyecto Tarifa \\
\hline & Proyecto Tarifa & \\
\cline { 2 - 3 } & Ensenada de Bolonia & Los Navíos-La Piedra que Revienta \\
\hline & & \\
\hline \multirow{5}{*}{ MÁLAGA } & Pecio de la Boladilla & Pecio de los Mármoles \\
\cline { 2 - 3 } & & \\
\cline { 2 - 3 } & Cañones del Saladillo & \\
\hline GRANADA & Cueva del Jarro & Portezuelo de los Baños \\
\hline ALMERÍA & Pecio Gandolfo & \\
\hline \multirow{5}{*}{} & Portezuelo de los Bajos & \\
\hline & & \\
\cline { 2 - 3 } & Pecio Dressel 20 - Pecio Medieval & \\
\hline
\end{tabular}

De los yacimientos citados en el cuadro anterior no fue posible visitarlos todos debido a problemas administrativos, al no obtener los permisos oportunos emitidos por las Capitanías Marítimas. Mientras que en algunos casos dichos permisos fueron denegados -Ensenada de Bolonia, Puente Carranza, Caño de Sancti Petri-, en otros se dilató tanto su consecución, que éstos llegaron en fechas muy avanzadas del año.

Esta circunstancia, ha impedido la ejecución de los trabajos previstos en aquellas zonas que presentan condiciones geográficas especiales, como es el caso de los yacimientos seleccionados dentro del litoral onubense. En éstos los trabajos arqueológicos quedan limitados a épocas concretas del año, debido a su localización cerca de la desembocadura del Guadalquivir y sometidos a continuos aportes fluviales.

\section{Cádiz}

En la provincia de Cádiz las circunstancias de actuación pueden considerarse excepcionales, si se tienen presentes los siguientes puntos:

a. Es la provincia andaluza con mayor tradición en lo referente a estudios arqueológicos subacuáticos, circunstancia que ha dado lugar a que se posea una mayor información sobre el patrimonio arqueológico subacuático.

b. La ubicación del Centro de Arqueología en la ciudad de Cádiz facilita el acercamiento a los yacimientos de la provincia.

c. Lo referido anteriormente ha tenido como consecuencia que desde el Centro de Arqueología Subacuática se desarrollasen tres proyectos de investigación arqueológica dentro de la provincia gaditana: Proyecto Tarifa: un proyecto experimental para la pro- tección y puesta en valor del PAS; Proyecto Bajos al NW de la ciudad de Cádiz y el Proyecto Trafalgar.

En consecuencia, en el litoral de la provincia de Cádiz el mayor porcentaje de los yacimientos visitados, a excepción de Los Navíos-La Piedra que Revienta, quedan enmarcados dentro de los proyectos anteriormente citados tal y como se reflejan en las siguientes líneas.

\section{Los Navíos - La Piedra que Revienta}

Con respecto al yacimiento Los navíos - La Piedra que Revienta, decir que se trata de un pecio posiblemente época moderna, en el que aún quedan restos de su artillería, en concreto un gran número de cañones de hierro, cuatro anclas de distintas proporciones así como otro tipo de material muy concrecionado, de composición metálica, cuya identificación no ha podido llevarse a cabo durante este primer acercamiento a la zona. (Fig.2)

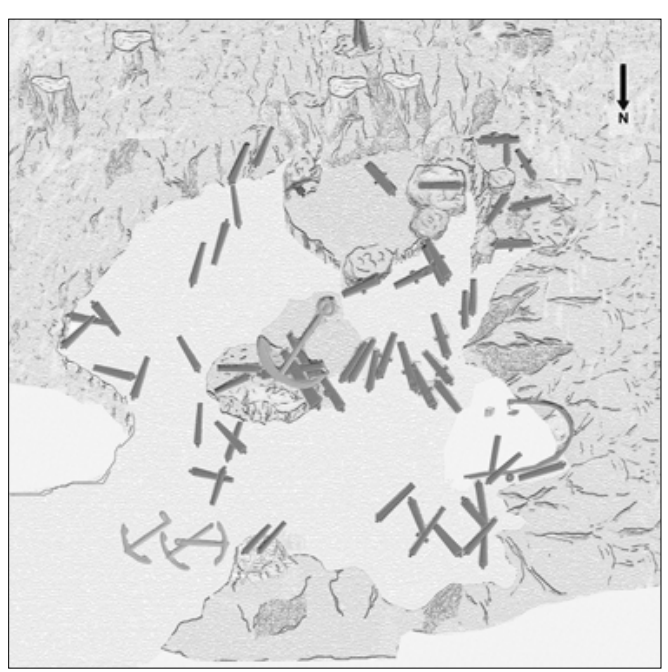

Fig. 2: Piedra que Revienta. 
En total se contabilizaron 61 cañones de hierro, teniendo noticias de la existencia de cañones de bronce, los cuales han sido extraídos por parte de expoliadores. Una prueba fehaciente de ello es la presencia, en el yacimiento, de una manga de succión de gran tamaño utilizada para retirar el sedimento depositado sobre el material arqueológico. Esta circunstancia ha traído consigo la pérdida de una valiosa información arqueológica, ya que los cañones de bronce cuentan, en su mayoría, con marcas y escudos que proporcionan una serie de datos importantes sobre el barco. De la misma forma, el registro arqueológico ha quedado destruido en una parte importante del yacimiento.

\section{Proyectos bajos al NW de la ciudad de Cádiz}

En el marco de las actuaciones de intervención llevadas a cabo en el desarrollo del Proyecto "Bajos al Noroeste de la ciudad de Cádiz" se han localizado o verificado, en otras ocasiones, la existencia de yacimientos arqueológicos situados principalmente en el entorno de La Caleta.

Esta actuación arqueológica subacuática fue aprobada mediante Resolución del 24 de septiembre de 1999 por el Director General de Bienes Culturales, bajo la dirección de Carmen García, Josefa Martí y Nuria Rodríguez.

Le Boucentaure II

Yacimiento definido por una serie de cañones y un ancla del tipo almirantazgo que corresponden a los restos de un pecio moderno. Actualmente se encuentra en un proceso de análisis con objeto de confirmar si se trata realmente del navío francés "Le Boucentaure" hundido en estas aguas.

Pecio Púnico del Canal de La Caleta

En un área relativamente amplia, con fondos de arena y fango, se aprecia una concentración de material, en principio de época púnica, semienterrado y aparentemente en buen estado de conservación.

Punta del Nao

Zona caracterizada por fondos de cascajos y grandes bloques de roca desprendidos del cantil de la Punta del Nao. En este entorno, se constata la existencia de abundante material anfórico romano y púnico.

\section{El Aculadero}

A través de la información oral aportada por buceadores que conocen la zona desde hace más de una década, se sabe de la existencia de un pecio enterrado que conserva el maderamen del casco y parte de su cargamento.

La cronología apunta a la época romana. En prospecciones superficiales se ha detectado la presencia de fragmentos anfóricos. El yacimiento se encuentra hoy día colmatado con aportes procedentes de la Bahía de Cádiz.

\section{La Albujera}

El yacimiento consta de abundante material anfórico romano de proporciones medias que semienterrado se concentra en un área reducida.
Pecio de la Sigillata

Sobre un fondo rocoso, y sorprendentemente en muy buen estado de conservación, se localizaron varias piezas de sigillata estampilladas asociadas a fragmentos anfóricos y pequeñas anclas de piedra.

\section{Piedras de Molino}

Se trata de un yacimiento compuesto de una serie de piedras de molino talladas, de distintos diámetros, encontrándose, desde el punto de vista espacial, muy concentradas.

Pecio del Ladrillo

Las fuentes consultadas arrojaban datos acerca de la existencia de unos restos de materiales constructivos de diversa índole que se dispersaban al pie de uno de los cantiles que caracterizan la zona.

Los restos, compuestos en su mayor parte por ladrillos alineados y por fragmentos de ánforas, no fueron localizados. Es de suponer que la dinámica litoral, cuyos efectos son pronunciados en este entorno, ha desarrollado un proceso de sedimentación ocultando cualquier indicio de material arqueológico.

\section{Proyecto Tarifa: un proyecto experimental para la protección y puesta en valor del Pas}

Dentro de este proyecto tuvo lugar una actuación arqueológica subacuática aprobada mediante Resolución del 4 de octubre de 1999 por el Director General de Bienes Culturales, bajo la dirección de María Navarro y Rocío Castillo.

Los resultados obtenidos en esta primera fase están siendo, en la actualidad, objeto de estudio. No obstante se puede adelantar una apreciación somera de aquellas zonas visitadas, dentro del entorno de la Isla de Tarifa, que han proporcionado resultados más interesantes desde el punto de vista arqueológico.

Piedras de Molino

Se trata de una agrupación de piedras de molino de gran tamaño concentradas en un espacio relativamente reducido.

Zona de Fondeo

Área definida por la existencia de un cepo romano así como numerosas anclas de piedra de distintos tamaños.

\section{Zona conocida como Pecio del San Andrés}

Restos de un barco de palas de hierro muy expoliado a lo largo de los años. A través de noticias orales se tiene constancia de que entre sus restos existieron lingotes de plomo, de 75 kilogramos, grabados con el nombre de SAN ANDRÉS, así como cerámica y botellas de cristal de la marca Schweppes.

Zona de las Laminarias

Caracterizada por la presencia de anclas de hierro y abundante material anfórico muy fragmentado y disperso. 


\section{Málaga}

Tras examinar los datos recopilados en trabajos anteriores se seleccionaron un conjunto de yacimientos localizados en el municipio de Estepona.

\section{Pecio de la Boladilla}

Las noticias sobre este yacimiento lo describen, tomando de base los restos del cargamento, ánforas y cepos, como un pecio de época romana. Estos hallazgos habían sido localizados por buceadores deportivos de la zona.

En los trabajos desarrollados por el Centro de Arqueología Subacuática no se detectaron más que algunos fragmentos de tégulas, así como pequeños restos anfóricos, dispersos en un fondo de rocas y arenas que caracteriza este entorno subacuático.

\section{Pecio de los mármoles}

Los datos aportados por noticias orales, hacen referencia a la existencia del cargamento de un pecio de época romana. Compuesto por un conjunto de bloques de mármol de forma rectangular y cónica, este cargamento bien pudiera haber sido destinado para la construcción.

Tras examinar la zona se localizaron, cerca de un pequeño espigón y sobre un fondo de arena, una agrupación de bloques de piedra sin que se registraran indicios de otros elementos arqueológicos.

Tras la toma de muestras de uno de los bloques, éstas fueron analizadas por D. Jesús Espinosa Gaitán, técnico del Centro de Intervención del Instituto Andaluz del Patrimonio Histórico. Para dicho análisis se aplicaron los métodos de difracción de rayos $X(D R X)$ y la microscopia óptica de luz polarizada, determinándose que se trataba de un tipo de roca dolomítica.

Actualmente es necesario llevar a cabo una fase de estudio que verifique, entre otros puntos, si este tipo de roca forma parte de la geología local de la zona y si su presencia responde a una acción de carácter accidental o intencionada.

\section{Pecio del padrón}

Pecio contemporáneo cuyos restos se concentren en un área relativamente reducida. La fortuita localización de los vestigios, de los cuales no se tenían referencias, fue fruto de los trabajos de prospección desarrollados en la zona con el objeto de hallar vestigios de otro yacimiento situado en las proximidades.

Entre los elementos más identificativos destacar la existencia de varios ojos de buey, conducciones en circuito cerrado, instrumental de navegación, planchas del forro del barco y la parte inferior del plan de sentina, así como una gran variedad de objetos metálicos pertenecientes a la estructura del navío. (Fotos $\mid$ y 2).

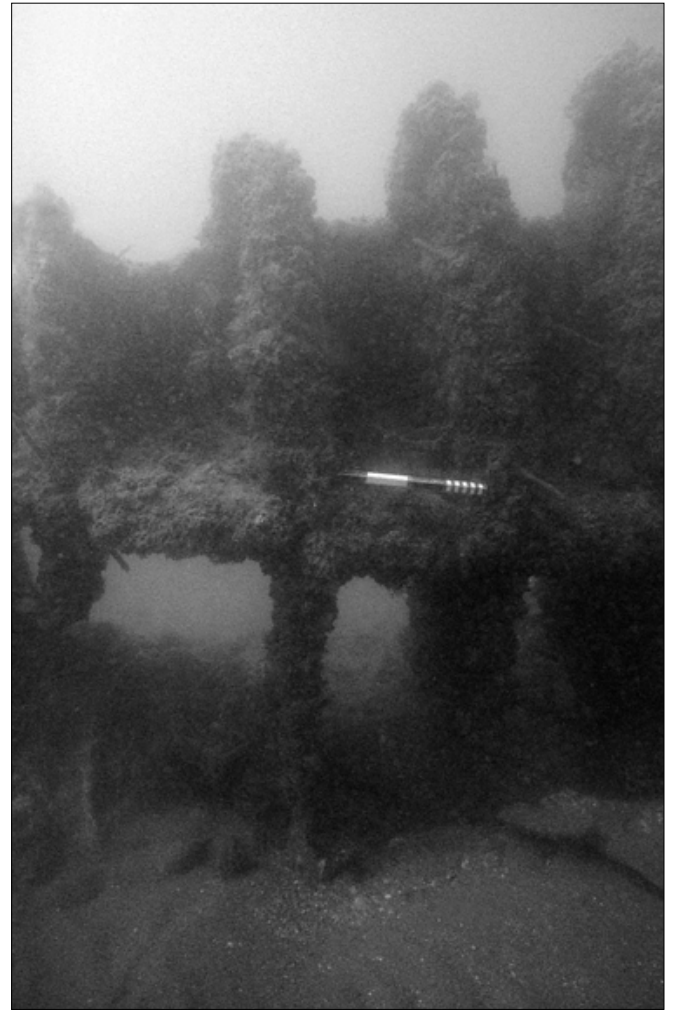

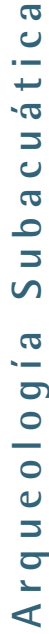

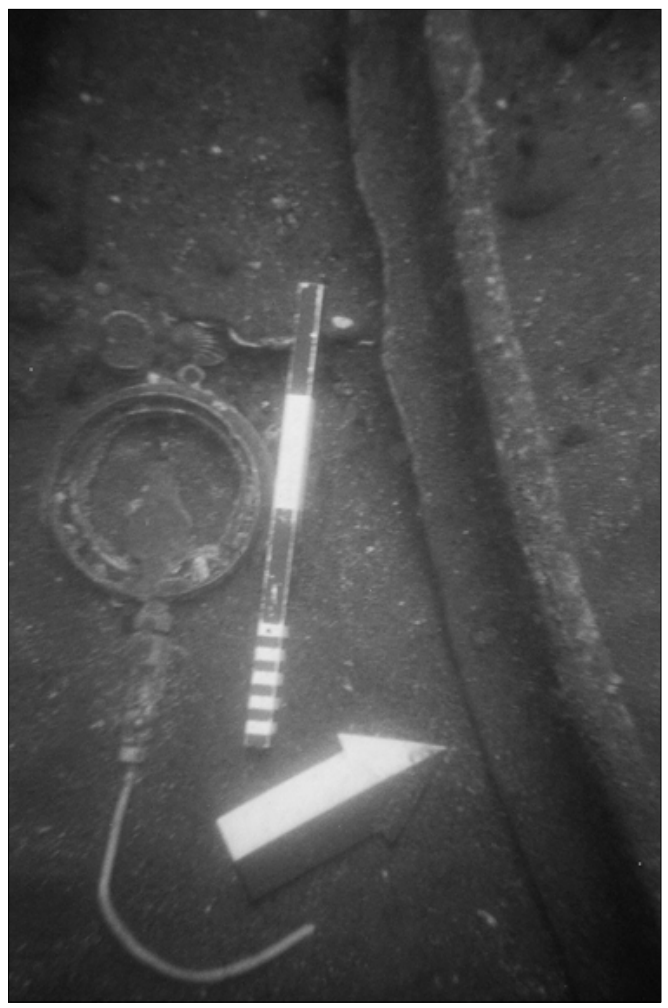

Foto I: Plan de sentina Pecio del Padrón.

Foto 2: Instrumental. Pecio del Padrón.

\section{Cañones del Saladillo}

Se trata de una zona donde se conoce la existencia de distintas agrupaciones de cañones, habiendo sido una de ellas objeto de una inspección arqueológica en el año 1993. El objetivo de la actuación arqueológica desarrollada por el CAS era localizar el resto de agrupaciones. 


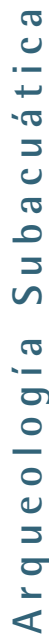

Fig. 3: Cañones del Saladillo

Foto 3: Vista frontal. Cañón del Saladillo.
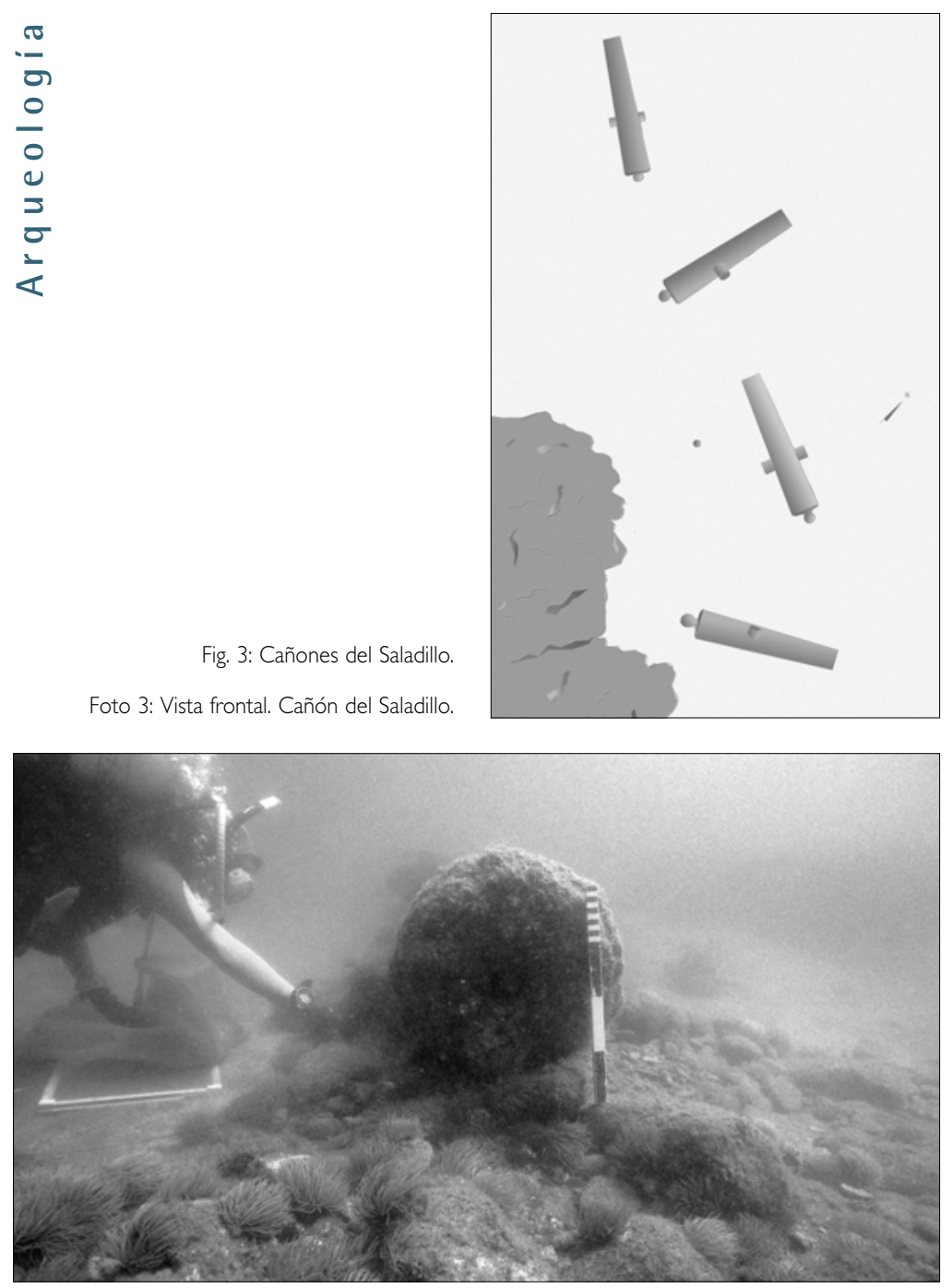

\section{Granada}

Cueva del Jarro

Yacimiento inscrito en la Base de Datos de los Yacimientos Arqueológicos de Andalucía, se describe como una zona de posible existencia de uno o varios pecios, griego o fenicio, donde se han recuperado abundantes restos anfóricos de diversa tipología y cronología, así como una coraza de bronce, indicándose que es una zona sometida a expolio desde los años 60.

Realizadas prospecciones circulares y siguiendo una filier, se pudo constatar la no existencia de restos arqueológicos en superficie, circunstancia que bien pueda ser consecuencia del expolio al que anteriormente se hacía mención.

\section{Almería}

\section{Pecio Dressel 20 - Pecio medieval}

El pecio Dressel 20 está constituido por ánforas Dressel 20 y posiblemente Almagro 5I, mientras que el medieval se corresponde con los restos de una nave medieval con un cargamento de loza azul y dorada (fuentes, platos, cuencos y tapaderas), así como fragmentos de un jarrón tipo Alhambra junto a lebrillos de vedrío verde y cerámica común.

Prospectada la zona de la laja de Cabo de Gata (Foto 4) -fondo de roca, arena, cascajo y posidonias-, se localizaron diversos restos metálicos y de madera correspondientes a barcos contemporáneos, teniendo uno de ellos 42,5 metros de eslora. Este barco había sido hundido tras desguazarse parte de la obra viva y la totalidad de la obra muerta. Encajados entre sus restos se localizaron escasos fragmentos cerámicos, pertenecientes a ánforas tipo Dressel 20, aunque éstos se encontraban dispersos y muy rodados (Foto 5 ).

\section{Portezuelo de los Bajos}

Calificado, en el Catálogo de Yacimientos Arqueológicos de Andalucía, como fondeadero natural habilitado mediante la disposición de un muelle, tras los trabajos de prospección arqueológica superficial, se pudo comprobar que tales restos se identifican con una formación rocosa natural comprendida entre los 0,3 y los 2 metros de profundidad. La disposición rocosa dificulta la maniobrabilidad de embarcaciones en la zona. De la misma forma, existe una carencia total de restos arqueológicos así como de pertrechos utilizados para el fondeo.

\section{Portezuelo de los Baños}

Descrito, en el Catálogo de Yacimientos Arqueológicos de Andalucía, como un espigón, que configura un fondeadero al interior, sepultado por sedimentos marinos. Debido a que el posible yacimiento se encuentra en tierra y cubierto por sedimentos de origen marino su estudio no quedaba englobado dentro de las visitas programadas por el CAS. Esta sedimentación se extiende a la zona sumergida colindante al yacimiento, por lo que no es posible encontrar restos en superficie. Prospectada la zona que lo rodeaba, en tierra, se comprobó la existencia de numerosos restos cerámicos así como estructuras arquitectónicas, de época romana.

\section{Pecio Gandolfo}

Este yacimiento se describe en la Base de Datos ARQUEOS como restos de un barco romano, dispuesto en dos zonas con indicios de madera. En la primera se localizan maderas de la tablazón inferior con agujeros dispuestos sistemáticamente para el enganche de pasadores de madera, mientras que en la segunda existen cuadernas, posiblemente in situ (SW-NE). Se constata abundante material cerámico. 
Prospectada la zona se pudo comprobar que en dicha área había tenido lugar un proceso de colmatación importante, estando en la actualidad el yacimiento cubierto por arena.

\section{CONCLUSIONES}

Tras esta primera toma de contacto se ha tenido la oportunidad de constatar el escaso conocimiento que se tiene sobre el Patrimonio Arqueológico Subacuático andaluz, así como el grado de expolio al que se ve sometido.

En este sentido cabe mencionar que entre los yacimientos seleccionados más cercanos a la costa, aquellos cuyos restos arqueológicos se componen, en un mayor porcentaje, de material cerámico, han desaparecido casi en su totalidad. De su existencia queda constancia gracias a noticias escritas y orales.

No obstante, aquellos restos compuestos por piezas de artillería (cañones principalmente), son detectados en un mayor número debido a la dificultad y el costo económico que supone la extracción de los mismos, aunque esta circunstancia sólo es transpolable a los cañones de hierro, no sucediendo lo mismo con los de bronce muy codiciados en el mercado negro. Cabe destacar que la mayoría de yacimientos en los que aparecen cañones, éstos no aparecen asociados a otro tipo de materiales arqueológicos (cerámica, madera, restos metálicos de menor tamaño...) fáciles de extraer.

Por otra parte, la dinámica litoral característica de cada zona ha dado lugar al cubrimiento de alguno de los yacimientos de los que las fuentes documentales habían aportado una serie de datos, siendo imposible su identificación y localización bajo la arena o el fango.

Esta primera fase ha servido de base para comenzar una nueva andadura en el litoral andaluz que en el caso de la provincia de Cádiz se inició en la década de los 80 .

Del mismo modo, se ha producido un acercamiento por parte de las Delegaciones Provinciales de Cultura a la problemática que supone el desarrollo de la Arqueología Subacuática, tomando conciencia de la importancia y del estado en el que se encuentra su Patrimonio sumergido que adolece de una investigación, protección y conservación adecuadas. Esta circunstancia debe solventarse a través de:

- Ampliar de los conocimientos acerca de posibles nuevos yacimientos y de los ya localizados.

- Aumentar y adecuar las medidas legales en materia de protección del PAS.

- Evaluar el grado de deterioro de cada uno de los yacimientos con el objeto de aplicar las técnicas de conservación apropiadas a cada uno de ellos.

- Necesidad de transferir a los agentes sociales el valor histórico, riqueza e importancia de su patrimonio.

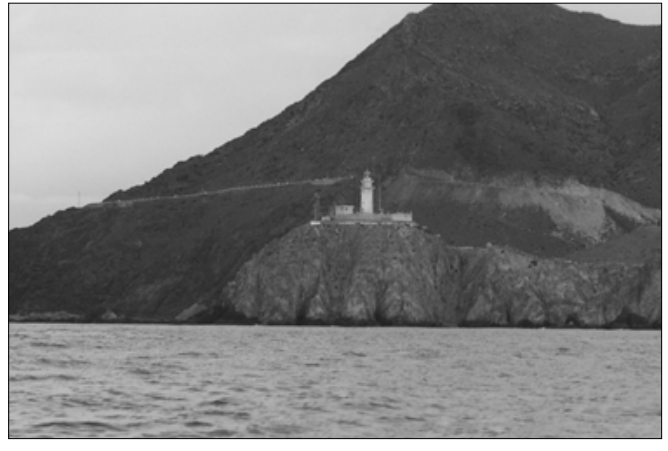

0
0
5
$-\pi$
2
0
0
0
2
0
0
$\frac{1}{0}$
0
$\frac{0}{0}$
0
2
0
1
$<$

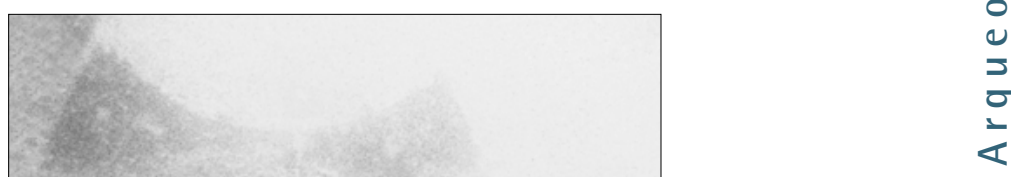

Foto 4: Vista general del Cabo de Gata.

Foto 5: Plan de bodega. Pecio del Cabo de Gata.

Por ello, no se debe olvidar que el mantenimiento, protección y conservación del Patrimonio subacuático sólo puede plantearse desde un conocimiento del mismo a través del estudio y la investigación de este tipo de yacimientos, tradicionalmente ignorados, antes de que su destrucción y desaparición sea irremediable.

\section{AGRADECIMIENTOS}

Las labores ejecutadas a lo largo de estas actuaciones arqueológicas han sido facilitadas, en gran medida, tanto por Instituciones Públicas como por particulares. Es por ello que quisiéramos agradecer la ayuda prestada por:

- las Delegaciones Provinciales de Cultura correspondientes.

- el Ayuntamiento de Estepona

- la Cofradía de Pescadores de Estepona.

- los arqueólogos Lorenzo Cara e lldefonso Navarro.

- los buceadores Juan Domingo Mayo, Luisa Aguilar, Juan Córdoba (Club Bahía); Francisco Guerrero, Félix Rodríguez (Club Caetaria); José Chicano (Club Crissed); Juan Ignacio Ardila (Club Áncora); Luis Miguel Villaescusa. (Club Granada Sub); Javier Abreu; Juan Villa; Antonio Rodicio y Daniel Sevillano. 